\title{
Evolution of MRI appearances due to progressive multifocal leucoencephalopathy following natalizumab treatment for multiple sclerosis
}

\author{
Sarah Campbell, ${ }^{1}$ Avinash Kumar Kanodia, ${ }^{2}$ Jonathan O'Riordan ${ }^{1}$
}

\begin{abstract}
${ }^{1}$ Department of Neurology, Ninewells Hospital, Dundee, UK

${ }^{2}$ Department of Radiology, Ninewells Hospital, Dundee, UK
\end{abstract}

Correspondence to Dr Avinash Kumar Kanodia, avinash.kanodia@nhs.net

Accepted 22 March 2015

\section{DESCRIPTION}

Progressive multifocal leucoencephalopathy (PML) is a devastating neurological condition caused by reactivation of JC virus (JCV), which targets oligodendrocytes resulting in widespread demyelination of subcortical white matter. It typically occurs in immunocompromised patients, most commonly in association with AIDS. $^{1}$ More recently, PML has been described in association with biological therapies. ${ }^{1}$ Natalizumab is a monoclonal antibody that is currently licensed as a single disease modifying therapy for patients with highly active relapsing remitting multiple sclerosis (MS). ${ }^{2}$ PML risk with natalizumab increases with JCV seropositivity, natalizumab treatment for longer than 24 months and previous immunosuppressive therapy. The usual MRI findings of PML tend to be different from the usual MS findings although overlaps can be present. We present serial MRI brain findings describing the evolution of changes from initial MS presentation to subsequent worsening, stabilisation of appearances while receiving Natalizumab therapy and development of PML with further worsening of appearances leading to our patient's current state.

We present the case of a 46-year-old woman who presented in 2007 with visual problems. She had pallor of the left optic disc, bilateral internuclear ophthalmoplaegia and an ataxic gait. A series of blood tests were either normal or negative. The initial MRI in February 2007 demonstrated some focal white matter changes, including periventricular and juxtacortical white matter (figure 1). Cerebrospinal fluid (CSF) analysis demonstrated intrathecal oligoclonal IgG. Accordingly, the patient was diagnosed with MS. Following a course of steroids, she was started on first line disease modifying therapy in the form of Glatiramer acetate. Unfortunately, she experienced two further severe relapses over the subsequent 10 months and was unable to ambulate. A repeat MRI in December 2007 demonstrated several new lesions in supratentorial and infratentorial compartments, many of these showing enhancement on contrast (figure 2).

Despite the fact that the patient was JCV positive, her treatment was escalated to natalizumab. There was a dramatic stabilisation in her MS such that her mobility returned and she only had minimal residual signs. Follow-up MRI in April 2009 was in keeping with her clinical state, and demonstrated reduced size and disappearance of some of the lesions while other lesions were stable. No new lesions were present (figure 3).

Her condition remained stable for the next 2 years. There was, however, a dramatic clinical worsening following cessation of Natalizumab because of pregnancy; it was subsequently restarted on a monthly basis and the patient stabilised once again. Initially she underwent yearly MRIs for monitoring

\section{-}

To cite: Campbell $\mathrm{S}$, Kanodia AK, O'Riordan J. BMJ Case Rep Published online: [please include Day Month Year] doi:10.1136/ bcr-2015-210305

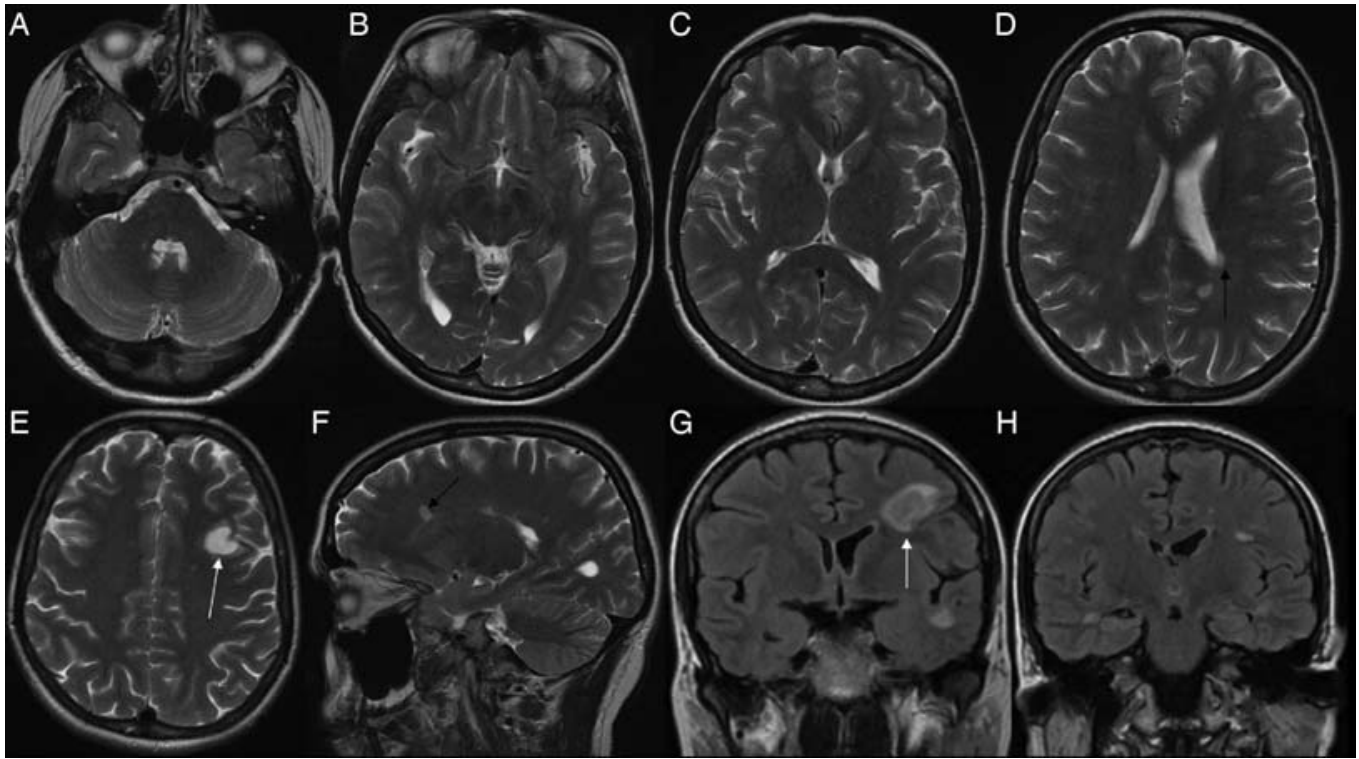

Figure 1 Initial presentation of MS. MRI in February 2007. (A-E) T2 axials, (F) T2 sagittal and (G,H) FLAIR coronals. Black arrows in (D) and (F) show periventricular lesions. White arrows in (E) and (G) show juxtacortical lesions. FLAIR, fluid-attenuated inversion recovery; MS, multiple sclerosis. 


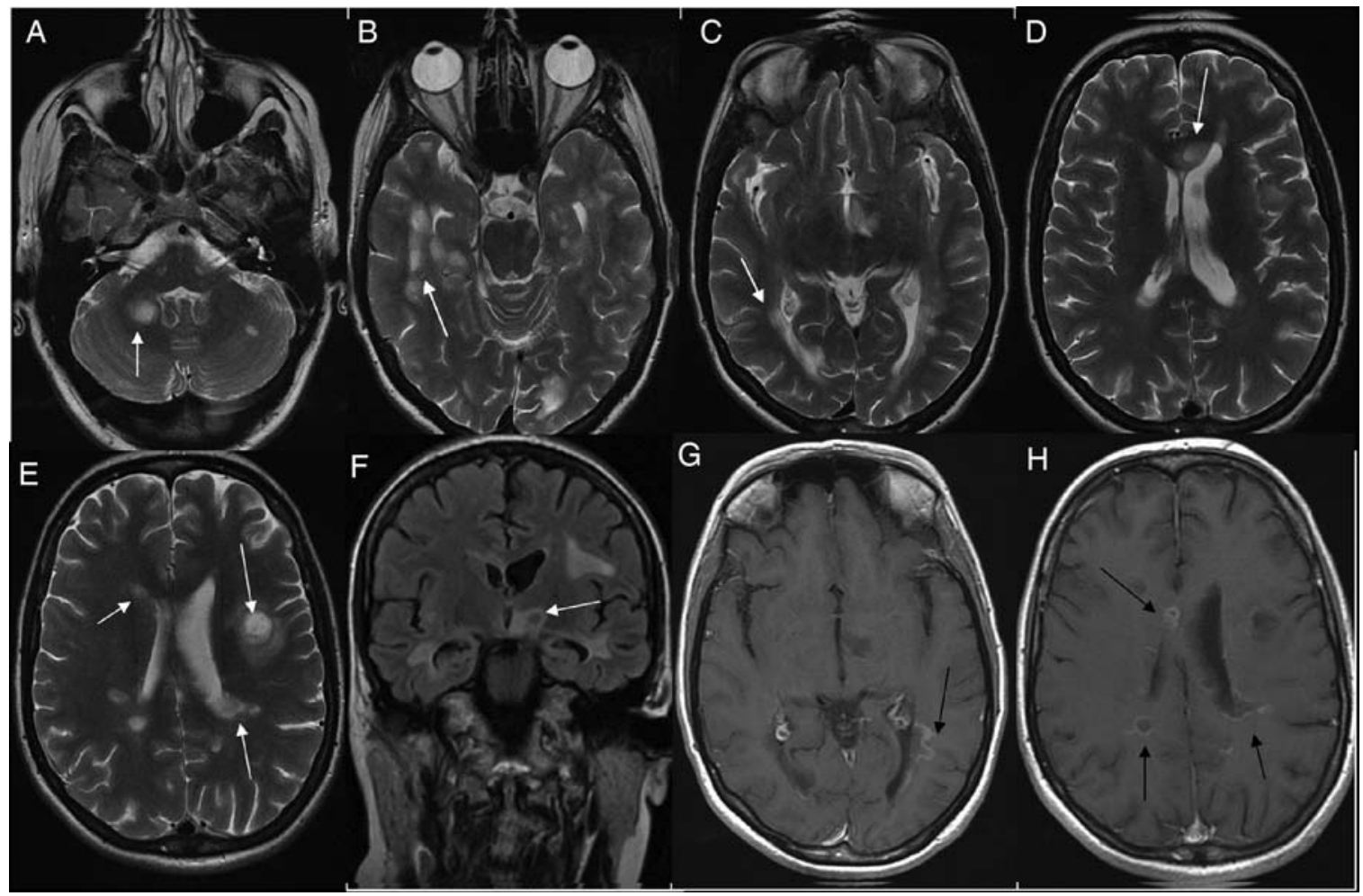

Figure 2 Progression in MRI in December 2007. (A-E) T2 axials, (F) FLAIR coronal, $(G, H)$ postcontrast T1 axials. White arrows in (A-F) show multiple new lesions in supratentorial and infratentorial compartments, including corpus callosum (white arrow in D). Black arrows in $(\mathrm{G}, \mathrm{H})$ show multiple enhancing lesions. FLAIR, fluid-attenuated inversion recovery.

purposes and her MRI scans were largely stable. An MRI performed in June 2013 showed stable appearances (figure 4) in comparison with her scan from 2009 (figure 3). At the end of 2013, the frequency of imaging was increased to every 6 months.
We also initiated a process of monthly monitoring of the JCV titre to assess preclinical rises.

In early 2014, unfortunately, the patient developed a subacute deterioration with worsening ataxia, cognitive decline and

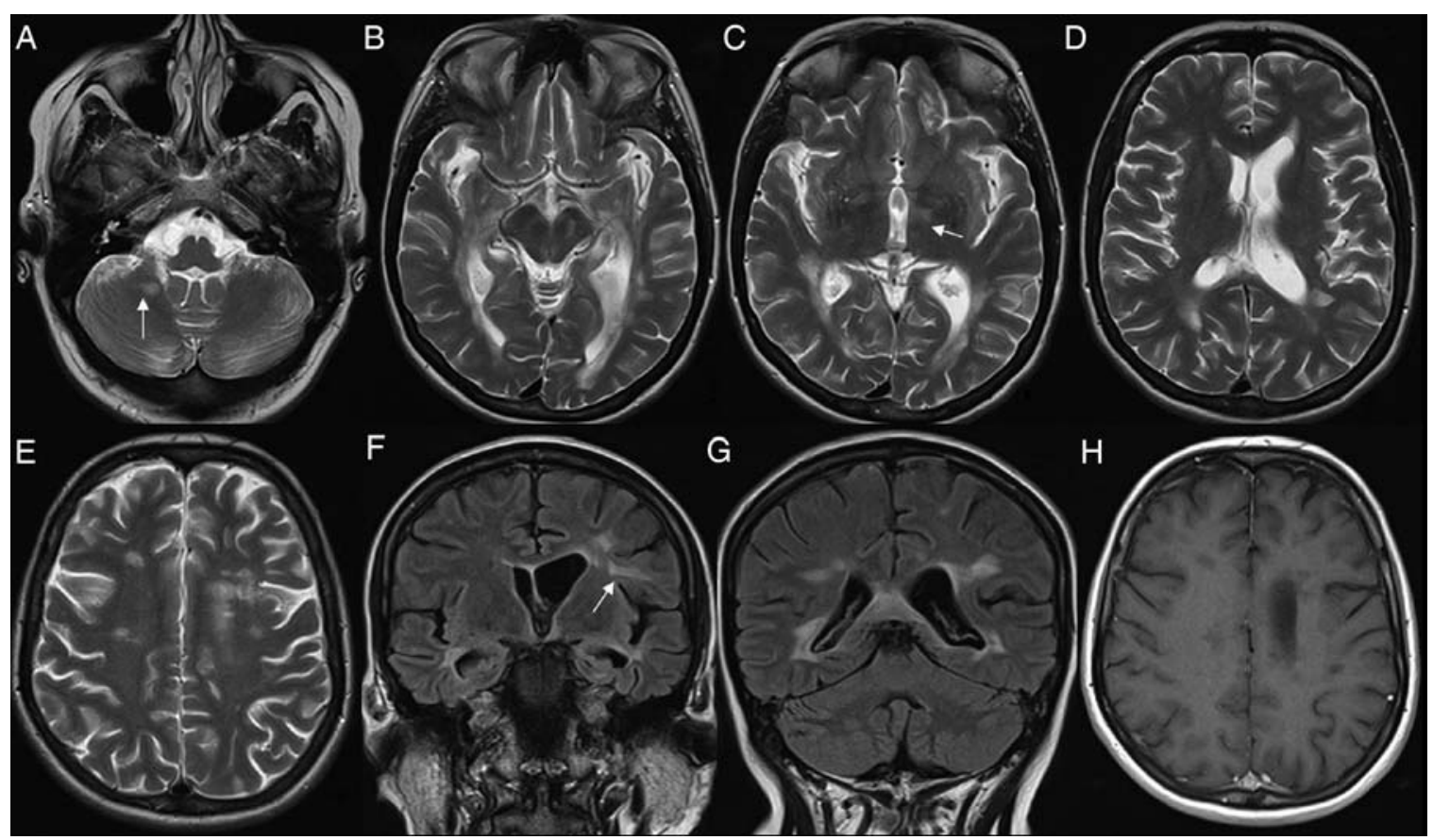

Figure 3 Follow-up MRI April 2009. (A-E) T2 axials, (F,G) FLAIR coronals, (H) postcontrast T1 axial. Multiple white abnormalities are again seen. Some of the lesions (white arrows in $A, C, F$ ) show some of the lesions improved or resolved as compared to figure 2, while other lesions are largely stable. No enhancing lesions are present in (H). FLAIR, fluid-attenuated inversion recovery. 


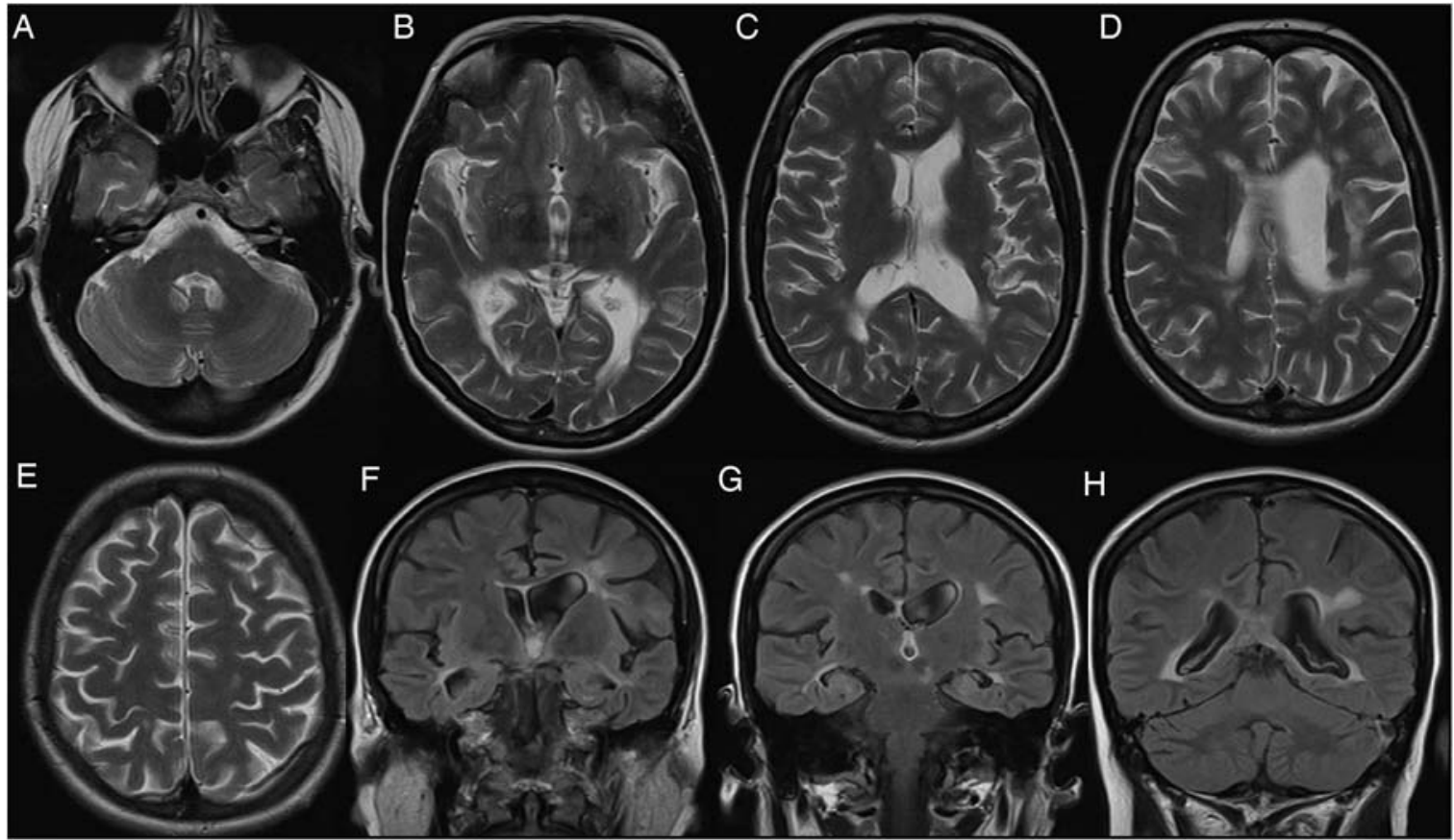

Figure 4 Follow-up MRI June 2013. (A-E) T2 axials, (F-H) FLAIR coronals. Largely stable appearances in comparison with figure 3, considering a gap of 4 years. FLAIR, fluid-attenuated inversion recovery.

spasticity. Her MRI in February 2014 showed several large new areas of abnormalities in subcortical white matter in the right cerebral hemisphere (figure 5). A concomitant antibody titre for JCV demonstrated a greater than fourfold rise when compared to a sample from 1 month previously. PML was suspected and confirmed on CSF analysis where 496 copies/mL of JCV DNA were detected. Natalizumab was discontinued and the patient underwent five courses of plasma exchange.
Her condition, unfortunately, continued to deteriorate. Over the course of 6 weeks her neurological condition deteriorated from being ambulatory independently to being bed bound with progressive left-sided weakness associated with an element of inattention. She developed frontal release signs and left homonymous hemianopia. An MRI in April 2014 demonstrated significant worsening including more confluent and diffuse signal changes in right cerebral hemispheric white matter, further

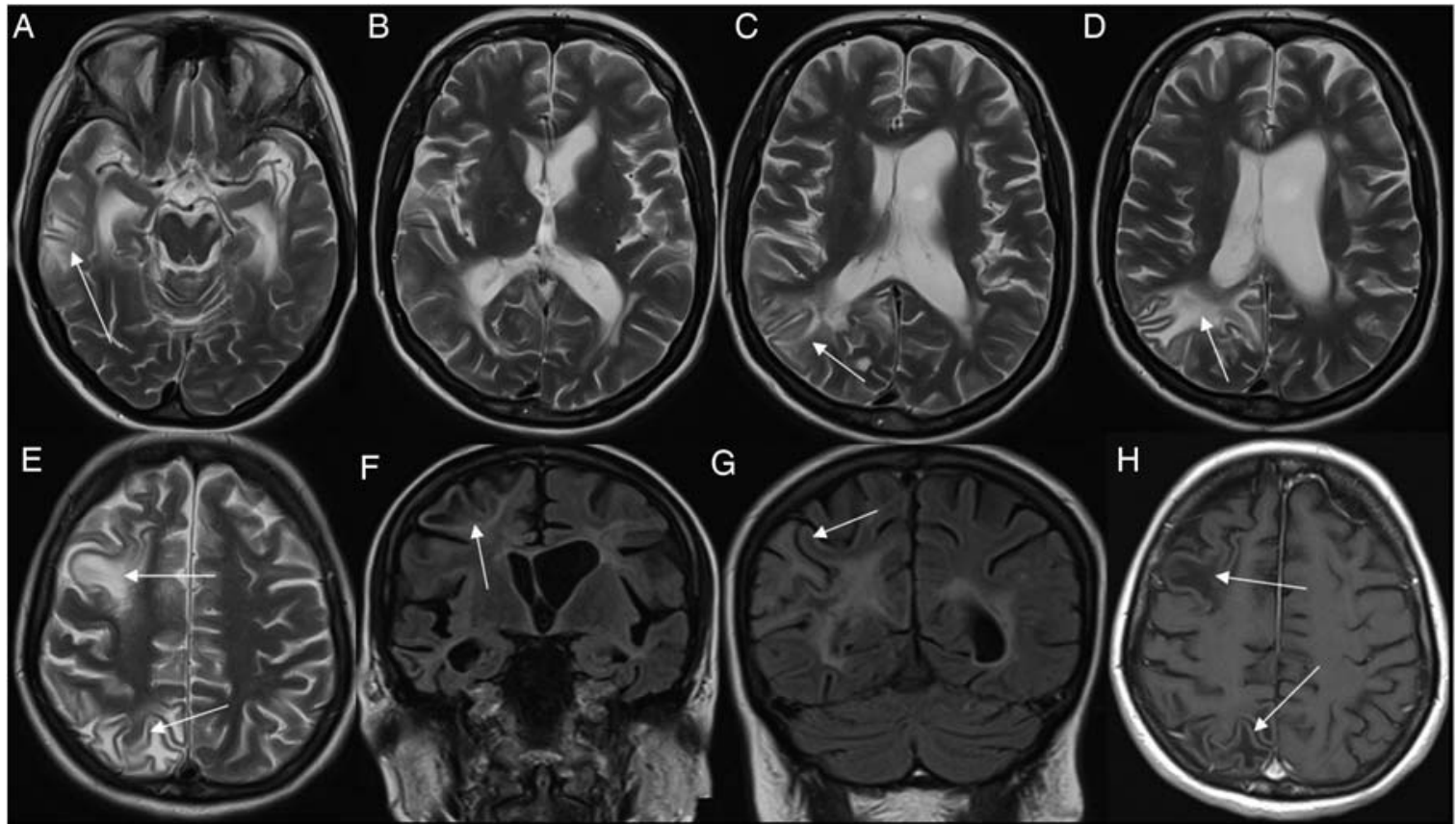

Figure 5 PML in MRI February 2014. (A-E) T2 axials, $(F, G)$ FLAIR coronals, $(H)$ postcontrast T1 axial. Multiple new large subcortical white matter lesions on right side (white arrows in A,C,D-H). No enhancement is seen in (H). PML, progressive multifocal leucoencephalopathy; FLAIR, fluid-attenuated inversion recovery. 


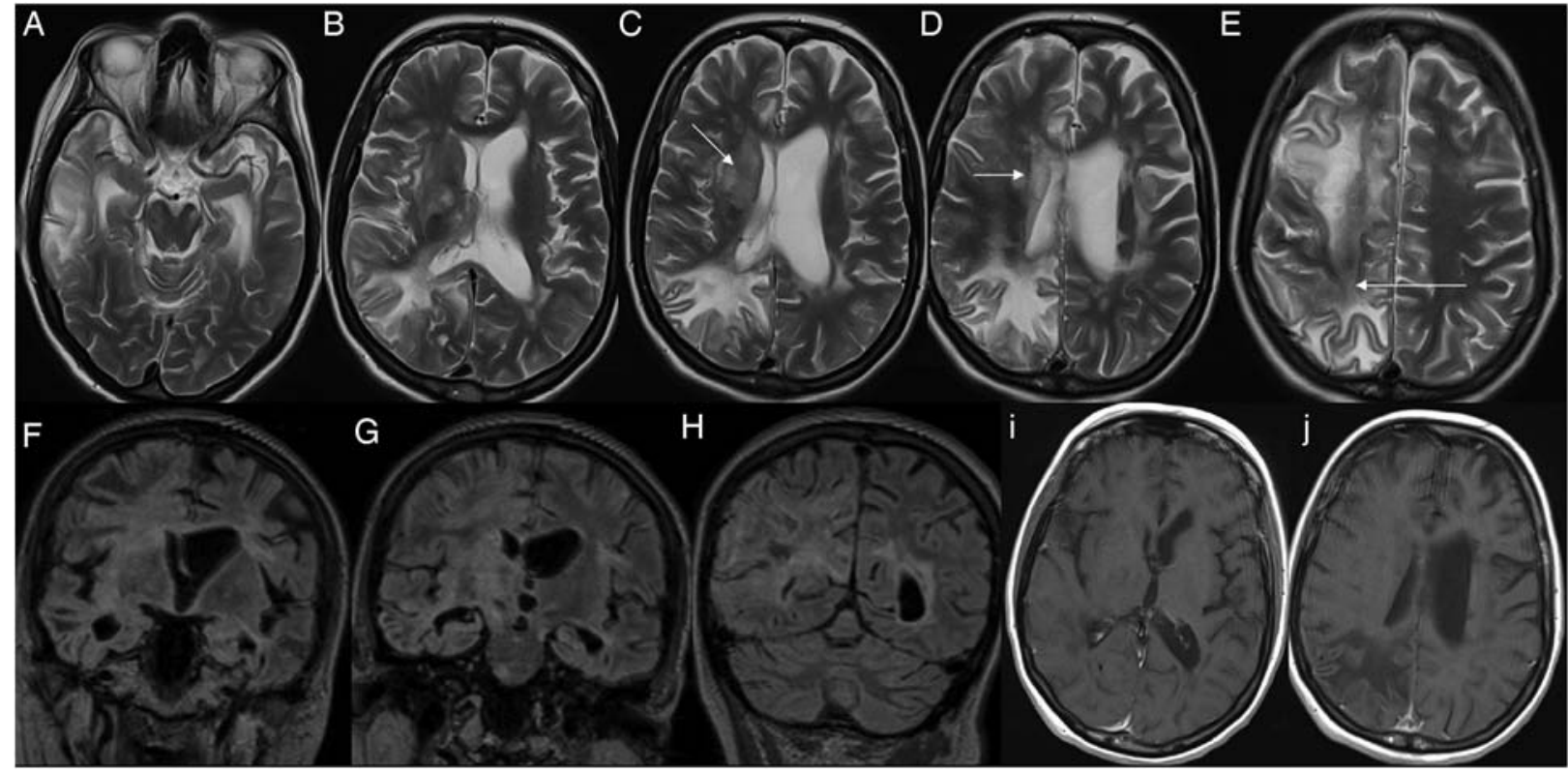

Figure 6 MRI April 2014. (A-E) T2 axials, (F-H) FLAIR coronals, (I,J) postcontrast T1 axials. There has been significant worsening of appearances as compared to figure 5. There are new areas of signal abnormality (white arrows in C-D) with more confluent changes. No enhancement is seen in $(I, J)$ to suggest IRIS. FLAIR, fluid-attenuated inversion recovery; IRIS, immune reconstitution inflammatory syndrome.

changes in deep nuclei and some further changes in left cerebral hemisphere. No contrast enhancement was present (figure 6).

Initially it was felt that she might have had immune reconstitution inflammatory syndrome, but her MRIs were never in keeping with this nor were her sequential CSF-JCV DNA 47 copies/mL 4 months later.

\section{Learning points}

- MRI of the brain plays a very important role in following up patients in multiple sclerosis (MS) on natalizumab therapy who have a high risk of developing progressive multifocal leucoencephalopathy (PML).

- Despite possible overlaps, MRI findings of PML and MS can be distinct enough to raise a reasonable suspicion of PML, particularly in appropriate clinical circumstances.

- For those patients who are JC virus positive, we recommend repeat MRIs at three monthly intervals for comparison.
Two courses of prolonged steroids were ineffective. She currently remains severely disabled with an Expanded Disability Status Scale (EDSS) of 9.

The serial MRI scans have been presented, demonstrating the evolution of appearances from initial presentation of MS to a highly deteriorated state with PML. These images demonstrate the effectiveness of MRI in following up such patients, emphasise the differences in usual imaging appearances of MS and PML, and reveal the important role MRI plays in confirming clinical suspicions that are of critical importance in patient management.

Twitter Follow Jonathan O'Riordan at @Dr Jonathan O'Riordan

Competing interests None declared.

Patient consent Obtained.

Provenance and peer review Not commissioned; externally peer reviewed.

\section{REFERENCES}

1 Ferenczy MW, Marshall LJ, Nelson CDS, et al. Molecular biology, epidemiology and pathogenesis of progressive multifocal leukoencephalopathy, the JC virus-induced demyelinating disease of the human brain. Clin Microbiol Rev 2012;25:471-506.

2 NICE guidelines. Natalizumab for the treatment of adults with highly active relapsing remitting multiple sclerosis. 2007.

Copyright 2015 BMJ Publishing Group. All rights reserved. For permission to reuse any of this content visit

http://group.bmj.com/group/rights-licensing/permissions.

BMJ Case Report Fellows may re-use this article for personal use and teaching without any further permission.

Become a Fellow of BMJ Case Reports today and you can:

- Submit as many cases as you like

- Enjoy fast sympathetic peer review and rapid publication of accepted articles

- Access all the published articles

- Re-use any of the published material for personal use and teaching without further permission

For information on Institutional Fellowships contact consortiasales@bmjgroup.com

Visit casereports.bmj.com for more articles like this and to become a Fellow 